\title{
Ergía y Pasítea: hacia un entendimiento cosmogónico de la pereza en la Antigua Grecia*
}

Recibido: 15/01/2021 | Revisado: 23/07/2021 | Aceptado: 25/08/2021

DOI: 10.17230/co-herencia.18.35.10

\author{
Juan David Almeyda Sarmiento** \\ juanalmeyda96@gmail.com
}

Resumen La presente investigación tiene por objetivo justificar cómo la pereza constituye una parte intrínseca de la sustancia humana dentro de la cosmogonía en la Antigua Grecia. Para ello, el escrito se divide en tres momentos. Primero, se hace una breve exposición de lo que implica el trabajo duro a partir de su personificación mitológica: Horme. Segundo, se sitúa a la skholè como un concepto en el que convergen la pereza y la contemplación en dirección a una capacidad reflexiva fundamentada desde el no-actuar. Tercero, se argumenta que Ergía y Pasítea son diosas que dan fundamento a pensar la pereza como una categoría ontológica dentro del entendimiento que el ser humano hace de sí mismo. Esto último, ya que son deidades que tienen su ubicación dentro de la constitución humana antes de la skholè, lo cual las ubica como fundamentales para el estudio del ocio en la Antigüedad.

\section{Palabras clave:}

Cosmogonía, descanso, Grecia Antigua, pereza, trabajo.

\section{Aergia and Pasithea: toward a cosmogonic understanding of laziness in Ancient Greece}

\footnotetext{
Abstract The present study aims to justify how laziness constitutes an intrinsic part of the human substance within cosmogony in Ancient Greece. To do so, the paper is divided into three parts. First, a brief explanation of what hard work implies is offered from its mythological personification: Horme. Second, skholè is regarded as a concept in which laziness and contemplation converge in the direction of a reflective capacity based on inaction. Third, it is argued that Aergia and Pasithea are goddesses that provide the basis for considering la-
}

* Este artículo es una investigación derivada de la tesis de Maestría en Filosofía "Hacia una ética del jardín: un análisis ético-político de la revolución del tiempo en el pensamiento de Byung-Chul Han", en la Universidad Industrial de Santander, BucaramangaColombia. 
ziness as an ontological category within human beings' understanding of themselves. The latter, inasmuch as they are deities that are found within the human constitution before the skholè, which places them as fundamental for the study of leisure in Ancient Times.

Keywords:

Cosmogony, Rest, Ancient Greece, Laziness, Work.
* * Profesor de la

Escuela

de Filosofía de la

Universidad

Industrial de

Santander,

Bucaramanga-

Colombia. ORCID:

0000-0002-6463.

6388.

Esta investigación, que se realiza a partir del método documentalbibliográfico con enfoque hermenéutico, profundiza en la manera en que se puede hablar de la pereza en un sentido ontológico, esto es, como un elemento que es propio del carácter del ser humano en calidad de criatura perteneciente a la naturaleza, en la Grecia Antigua. Para ello, se recurre a la explicación cosmogónica presente en distintos textos de la tradición griega, como lo son los de Hesíodo, Píndaro y Homero, acerca de Ergía y Pasítea. Estas dos divinidades son cruciales para comprender cómo el griego de la Antigüedad se entiende en su contexto como un ser más allá de las obligaciones y profanaciones del trabajo para dar paso a una interrupción divina en la que se puede desviar lo impuro hacia una experiencia religiosa de conexión con la comunidad y con el mundo. De esta manera, el griego puede concebirse como un ser capaz de comprender la verdad de las cosas por medio de una contemplación, que sustituye el puro actuar por una skholè, en la cual se puede pensar sin el ruido de las tareas cotidianas. Todo esto en un ataque directo al entendimiento del mundo como un puro trabajar producto de la adoración a Horme, una divinidad útil para la humanidad, pero que fácilmente toma control de ella como un impulso que busca el dominio de la economía por sobre todo lo demás.

De esta manera, se quiere pensar a Ergía como una personificación que está en íntima relación con Hipnos, debido a su vínculo como guardiana de este (y a su vez por la dependencia que tiene con Pasítea), algo que la convierte en una parte necesaria e intrínseca de la existencia humana. Por lo tanto, se concluye que no se puede pensar la vida sin la presencia inmanente de la pereza en el alma humana. 
Ahora bien, esta reflexión sobre la cosmogonía griega quiere complementar la respuesta a una pregunta planteada por Erich Fromm (1995) sobre si el ser humano es perezoso por naturaleza. Más que debatir sobre las tesis del autor, se toma como antecedente dicha interrogación para poder justificar, desde un estudio de la mitología de la Antigua Grecia, por qué el ser humano sí tiene dentro de su constitución más profunda un "pequeño rincón de pereza" (un noactuar fundacional), por usar un término de Roland Barthes (1993, p. 53), que puede ser tomado como un punto de inflexión para criticar el dogma del trabajo duro como una forma paradigmática de vida para el porvenir de la humanidad.

\section{Horme: las dos caras del trabajo}

En la Antigua Grecia existe un recelo en lo que respecta, a nivel general, al trabajo y, en especial, con el exceso de este. La idea de descomponerse en el ejercicio de una labor hasta el completo cansancio no es algo propio de las virtudes rescatadas por los pensadores griegos. ${ }^{1}$ De ahí que la actividad, el impulso inicial para hacer algo, sea objeto de análisis dentro de su cosmovisión; la religión de los antiguos griegos permite darle una forma y un contenido religioso a la acción. Así, con Horme se personifica este esfuerzo inicial que era alabado dentro de las polis en un intento por obtener el favor del actuar:

Los atenienses tienen también en el ágora, entre otras cosas no conocidas de todos, un altar a Eleo, que es el más útil entre los dioses para la vida humana y las vicisitudes de la fortuna, y al que sólo los atenienses entre los griegos tributan culto; no sólo han instituido el amor a los hombres, sino que son piadosos con los dioses más que otros, $y$, efectivamente, tienen un altar en honor de Aidos, de Feme y de Horme, y es muy claro que los que tienen más piedad que otros tienen una buena fortuna equivalente (Paus. I 17,1$)$.

Esta última cita es la única referencia a esta encarnación de la actividad en la cosmogonía de la Antigua Grecia; sin embargo, eso no imposibilita intentar captar sus efectos dentro de la cotidianidad

La investigación de Vernant explica con mayor claridad esta idea (2003, pp. 5-22). 
y la idiosincrasia que el griego tiene respecto de la actividad y, más aún, de la hibris que el exceso de dicha actividad puede desencadenar. Horme tiene la particular cualidad de situarse como la posibilitadora del actuar aunque, claro está, el tipo de actuar que surge de esta deidad no refiere a la acción cotidiana como lo es el alimentarse, el caminar, etcétera, sino que su acción está concatenada a un apetito ${ }^{2}$ que es necesario para el trabajo duro y, en particular, para el que requiere un esfuerzo físico y corporal para ser realizado; de ahí que sea venerado junto al pudor (Aidos), la fama (Feme) en el templo al dios de la piedad (Eleo), en gran proximidad y relación con Atenea y Zeus. En conjunto, la alabanza a Horme conduce a un mesurado control sobre la acción dirigida al esfuerzo sobre las artes (tekhné) y la agricultura. Así, surge una distinción entre lo que es el mero actuar y la acción conducida a servir para el trabajo, entendiendo este último como un esfuerzo desgastante.

Sin embargo, Horme tiene proximidad con Eris. La diosa de la discordia siembra la competitividad dentro de la posibilidad de trabajar, lo que coloca a la envidia como un fenómeno que surge en el diario vivir. ${ }^{3}$ En la cosmogonía de la Antigua Grecia, el trabajo duro desencadena la competencia con el vecino, esto es, el afán de los artesanos, mercaderes y campesinos por formar riqueza, no necesariamente de formarse en virtud; este tipo de labor hace que la discordia aparezca y eche raíces la envidia, siendo esta última el

2 Cicerón se dio cuenta de la posibilidad que tiene Horme ya no como personificación divina, sino como un concepto desencantado para el funcionamiento del espíritu humano: "Ahora nos encontramos con que la actividad esencial del espíritu es doble: una fuerza es el apetito (es decir, $\delta \rho \mu \eta ́$, en griego), que impulsa al hombre de esta manera y de aquella; la otra es la razón, que enseña y explica qué se debe hacer y qué se debe dejar sin hacer. El resultado es que la razón manda y el apetito obedece" (Cic. Off. I, xxviii, 101).

3 En este sentido, hay que tener presente el rol que juega la discordia y sus hijas dentro de la caracterización que la cosmogonía hace del alma humana: "[L]a maldita Eris parió a la dolorosa Fatiga, al Olvido, al Hambre y los Dolores que causan llanto, a los Combates, Guerras, Matanzas, Masacres, Odios, Mentiras, Discursos, Ambigüedades, al Desorden y la Destrucción, compañeros inseparables, y al Juramento, el que más dolores proporciona a los hombres de la tierra siempre que alguno perjura voluntariamente" (Hes. Th., 230). Así, Eris es entendida como una encarnación de la amargura sobre la Tierra; su relación con Horme, por ende, solamente puede tener, en su esencia, la cualidad del vicio, algo que se puede comprobar con la reciprocidad que el mismo Hesíodo describe entre ambas deidades en Trabajos y días. Jean-Pierre Vernant encuentra en el trabajo, igualmente, una experiencia existencial de desgaste y limitación (2000, pp. 74-75). 
motor de todo trabajo. ${ }^{4}$ La relación entre Eris y Horme tiene dos caras: la amarga y la que bendice, de ahí que a la hora de entender el trabajo que se desenvuelve en la cotidianidad del mundo en la antigua sociedad griega sea menester entender cómo los límites deben mantenerse para que siempre exista una bendición y no un castigo. De esta idea, precisamente, habla Hesíodo:

A la otra [la Eris que bendice] la parió primera la Noche tenebrosa y la puso el Crónida de alto trono que habita en el éter, dentro de las raíces de la tierra y es mucho más útil para los hombres: ella estimula al trabajo incluso al holgazán; pues todo el que ve rico a otro que se desvive en arar o plantar y procurarse una buena casa, está ansioso por el trabajo. El vecino envidia al vecino que se apresura a la riqueza -buena es esta Eris para los mortales-, el alfarero tiene inquina del alfarero y el artesano del artesano, el pobre está celoso del pobre y el aedo del aedo (Hes. Op., 20-25). ${ }^{5}$

Esta manera de entender el trabajo y, por extensión, de vivirlo, se toma como una forma de limitar los impulsos descontrolados de los trabajadores que se encargan de ejercer la tekhné. En la vida cotidiana, Eris, ya sea como maldad o bendición, afecta de forma directa la acción de trabajar. La sociedad se sostiene sobre el trabajo, eso es cierto, pero este no se venera como una completa bendición, pues es menester tener en cuenta la manera en que se considera el exceso de trabajo por la mera riqueza como un elemento de vicio para el ciudadano griego. ${ }^{6}$ La sabiduría surge allí donde el trabajo cumple con su utilidad, sacia una necesidad, pero no en la búsqueda de obtener un beneficio puramente personal como el exceso de fama

4 Nietzsche, por su parte, encuentra que esto es algo que el griego de la época no elimina de su propio entendimiento, sino que aprende a vivir con ello: "Toda la antigüedad pensaba del rencor y la envidia de otra manera que nosotros [...] El griego es 'envidioso' y consideraba esta cualidad no como una falta, sino como una divinidad "bienhechora"' (2013, p. 63). Para Nietzsche, Eris era una diosa de adoración por la fortuna que trae la envidia al interior de la comunidad, aunque, igualmente, temiendo los infortunios que puede llegar a provocar.

5 Una comprensión de la relación entre Eris y Horme se puede apreciar mejor si se revisa la reflexión de Hesíodo en su griego original (Op., 20-25). Horme se presenta como una conducta dominada por Eris, la cual puede acontecer tanto para la amargura como para la bendición, pero los límites entre estas dos no son fácilmente identificables dentro de la vivencia del trabajo cotidiano del griego de la época.

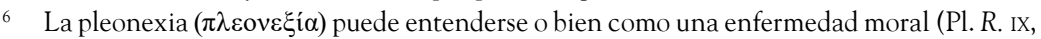
590b), como injusticia (Arist. EN Iv, 1122a) o como producto de un castigo de los dioses; para esto último véase el mito de la caja de Pandora (Hes. Op., 90-95). 
o de dinero. La virtud se encuentra en mantener el trabajo dentro de sus propios límites para poder establecer una vida en la esfera pública que sirva al bien común. No es de extrañar, entonces, la reflexión de Hesíodo inmediatamente después:

¡Oh Perses!, grábate tú esto en el corazón y que la Eris gustosa del mal no aparte tu voluntad del trabajo, preocupado por acechar los pleitos del ágora; pues poco le dura el interés por los litigios y las reuniones públicas a aquel en cuya casa se encuentra en abundancia el sazonado sustento, el grano de Deméter, que la tierra produce. Cuando te hayas provisto bien de él, entonces sí que puedes suscitar querellas y pleitos sobre haciendas ajenas (Hes. Op., 30).

De modo que el impulso, el appetitus, que caracteriza la presencia de Horme está estrechamente vinculado con la discordia. El trabajo, así entendido, se encuentra en una tensión constante entre ser realizativo y ser autodestructivo. Horme, por su interrelación con Eris, posee dos especies sobre la tierra; la primera, permite el funcionamiento de las ciudades por medio del trabajo de los pobres, la clase media y los esclavos, el cual está relacionado con el ejercicio de una tekhné, en la mayoría de los casos, y mantiene las necesidades básicas de la polis suplidas; la segunda, se corresponde con el exceso de trabajo, el cual puede desenvolverse en dos partes: una, el amo que explota a sus esclavos y sirvientes de manera exasperada para poder lucrarse de forma abundante de las bondades del campo; dos, los artesanos y mercaderes que buscan la autocomplacencia por medio de trabajar hasta desgastarse no para suplir sus necesidades, sino para lograr riqueza en demasía.? Esta naturaleza del trabajo permite concluirle dos dimensiones en la antigua sociedad griega: (1) la dimensión cívica,

\footnotetext{
Esta es una reflexión que Jenofonte remarca a partir de Sócrates y Eutidemo: "[Eut.] Pero ¿cúal de los elementos de la felicidad podría ser discutible? [Soc.] Ninguno, a no ser que añadamos la belleza, la fuerza, la riqueza, la fama o alguna otra cosa parecida. [Eut.] Pero es que tendremos que añadirlas, ipor Zeus!, pues ¿como se podría ser feliz sin ellas? [Soc.] [...] muchos a causa de la riqueza se envician y van a parar a la perdición, víctimas de asechanzas; y muchos también a causa de su fama e influencias políticas sufrieron grandes desgracias. [Eut.] Es que si tampoco puedo hablar bien de la felicidad, entonces reconozco que no sé lo que hay que pedirles a los dioses" (1993a, Mem. IV, 34-36). En respuesta a Eutidemo, se puede decir, como se verá más adelante, que lo que hay que pedirles a los dioses es la capacidad de renunciar al trabajo, esto es, de entenderse con la pereza como un no-actuar que posee una fuerza que equilibra la vida del ser humano.
} 
que se relaciona íntimamente con la política y la ética al interior de la polis y que se localiza en el entendimiento realizativo del trabajo y (2) la dimensión económica, que se vincula con la mera vida y que no propende hacia virtud alguna, solo busca la riqueza por la riqueza misma; esta dimensión se ubica en lo autodestructivo del trabajo. ${ }^{8}$

Es precisamente este trabajo cívico el que es destacado por Hesíodo, no es meramente un trabajar por la riqueza, que es un agregado del trabajo, sino que la acción, que es la base de este último, implica una oración. ${ }^{9}$ El trabajo no es pura economía, sino que es un ejercicio de devoción, los dioses aprecian el laborar. Horme, en este sentido, es una deidad piadosa y amarga, como la misma Eris. La economía, en cuanto acumulación de la riqueza por medio de la explotación vía trabajo, era de cuidado, el exceso de dinero es objeto de fama únicamente con el ejercicio mesurado que implica la actividad hacia el trabajo (Saavedra, 2007, p. 234). Lo cívico radica allí donde el ciudadano puede mantener un dominio sobre su actividad principal de sustento, actividad por demás perteneciente a la esfera privada, a la vez que permite la marcha adecuada de la polis:

Por los trabajos se hacen los hombres ricos en ganado y opulentos; y si trabajas te apreciarán mucho más los Inmortales [...] El trabajo no es ninguna deshonra; la inactividad es una deshonra. Si trabajas pronto te tendrá envidia el indolente al hacerte rico. La valía y la estimación van unidas al dinero. Para tu suerte, según te fue, es mejor trabajar, si olvidado de haciendas ajenas vuelves al trabajo tu voluble espíritu y te preocupas del sustento según mis recomendaciones (Hes. Op., 310-315). ${ }^{10}$

8 Para este punto, el pensamiento de Jenofonte vuelve a ser pertinente, su crítica a la riqueza permite apreciar una manera de entenderse con el trabajo suficiente, como lo demuestra el diálogo entre Sócrates y Critóbulo: "[Soc.] [...] tampoco la tierra es un bien para el hombre que la trabaja hasta el punto de que su cultivo le perjudica. [Crit.] En efecto, tampoco es riqueza si en vez de mantenernos nos hace pasar hambre [...] [Soc.] [...] las mismas cosas son bienes para quien sabe utilizar cada una de ellas y no son bienes para quien no sabe utilizarlas" (1993b, Oec., 8-10).

9 Vernant (1983) encuentra esto, especialmente, en esta concepción de Hesíodo. Para este último existe una areté en el trabajo, de la cual todo ser humano debe formar parte (1983, pp. 255-256).

10 Esta idea del trabajo como bendición y como maldición implica que, mientras que se tenga la capacidad de generar umbrales que separen el trabajo de la vida más allá de este, es posible una phronesis en lo que respecta al trabajo. En este sentido, tiene que haber un momento para el no-trabajo, solo así se evita la hibris producto de la (auto) explotación desde el trabajar. Estas virtudes del trabajo que destaca Hesíodo van hacia el trabajo cívico, pues es el que no se reduce al vicio de la ambición y la avaricia, siendo 
El trabajo cívico es el que conoce sus propios límites y, por extensión, le permite conocer su propia areté. Horme tiene en su justo medio aquello que lo dota de una excelencia frente al puro deseo de riqueza. La sofrosine surge de Horme a partir de la capacidad de mantener una conciencia con el mundo en el que se trabaja, esto es, cuando se piensa en el bien común y no en el mero interés personal. El correcto ejercicio de la acción hacia el trabajo constituye un carácter en aquel que debe trabajar, de ahí que, más allá de los artesanos y mercaderes, el cumplir con las obligaciones de las magistraturas y de los demás cargos públicos dentro de la polis fomenta una virtud, el desempeño es lo que dota al trabajo de excelencia, la riqueza es secundaria; inclusive, la acumulación de dinero no puede estar por encima del deber cumplido. Trabajo tras trabajo, dice Hesíodo, es como se consigue una riqueza, pero cada trabajo es una actividad que se realiza de forma plena y digna por quien la ejecuta, no es un mero producir por cumplir, sino que es un cumplimiento que da por resultado un bien, sea este del tipo que sea, ahí es donde se ubica la virtud del trabajo cívico: "Si en tu corazón el deseo te hace aspirar a la riqueza, actúa así y obra trabajo tras trabajo" (Hes. Op., 380). Es allí donde se entiende el tipo de trabajo que satisface y que no a las divinidades, la acumulación no es un orar con los dioses, sino que es una utilización de ellos, algo que no suscita un balance dentro de la dinámica de la cosmogonía de la Antigua Grecia.

El retorno a casa, el dejar-de-trabajar, es necesario para que la felicidad sea completa, esto no es una incitación a la holgazanería, la cual hay que distinguir de la pereza (sobre la que se profundizará más adelante) o el cansancio. El trabajo debe ser cortado, dentro del entendimiento del mundo se requiere dejar descansar el espíritu: "Anticípate a él y regresa a casa cuando termines el

estos últimos propios del dominio económico del trabajo. Es bajo esta idea que Píndaro (1984a) habla del hastío que, inevitablemente, surge del trabajar: "Para espléndidas hazañas el camino válido de las palabras / empieza desde la propia casa. Mas dulce es / el descanso en toda obra. Hastío / causa hasta la miel y las gozosas flores de Afrodita. / Por naturaleza diferimos cada uno, al obtener la vida por destino: / el uno ésta, aquella otros. Imposible es que uno solo / retenga para sí felicidad completa [...]" (N. VII, 55). Es importante entender que el cuerpo no soportará el exceso de trabajo producto de la presencia de la amarga Eris con Horme, como señala Píndaro, ya que, si no aguanta los excesos frente a los placeres, mucho menos lo hará con los vicios. 
trabajo, no sea que algún día te cubra desde el cielo una nube sombría y deje húmedo tu cuerpo y empapados tus vestidos" (Hes. Op., 555). Las lluvias amenazan con malestar al cuerpo desgastado. La hibris está allí donde Horme se hace presente sin tener la temperancia requerida para la areté del trabajo, el cual solamente puede ser cívico para lograr que el miembro de una polis tenga una vida feliz y completa.

\section{Skholè y el entendimiento de la vida más allá de la pura actividad}

$\mathrm{Al}$ volver a casa se debe afrontar un nuevo tipo de relación con el mundo. El umbral entre trabajo y no-trabajo es lo que posibilita un encuentro con la evasión de la realidad de Horme, tanto de su dimensión cívica como económica. Existe otra relación del alma con su existir que se encuentra no en el trabajo duro, en el desgaste diario del trabajar, en el tiempo activo, sino en el tiempo libre. Esta relación entre sujeto-tiempo hace posible un nuevo tipo de vigor que no es permitido dentro del rígido esquema que impone Horme: "También ahora testimonia Alcímidas que lo innato en él / se parece a los prados fructíferos que, cambiantes, / unas veces, en efecto, dan de sus llanos vida añal a los hombres, / otras, en cambio, descansando (a barbecho) reponen vigor [...]" (Pi. N. VI, 10).

El trabajo honrado es una alabanza a los dioses, pero, en la misma medida, la phronesis frente al trabajo requiere de un notrabajar, esto es, de despejar el espíritu de la pura actividad con la que Horme imbuye a quienes le rezan. El exceso de impulso, de appetitus, deja al cuerpo y al alma maltrechos; el no evadir el peso que conlleva el trabajo hace que no sea posible un amor hacia lo bello y lo bueno que constituye la existencia dentro de la polis, de ahí la advertencia que Circe le hace a Ulises: "Vamos, pues, pon la espada en la vaina y ahora sin tardanza a mi lecho subamos los dos, por que unidos en descanso y amor confiemos el uno en el otro" (Hom. Od. x, 330). Es allí donde entra la skholè como una práctica del no-trabajar, o bien, como un estado en el cual se logra un ejercicio de la vida más allá de la economía del trabajo y 
del civismo como una mera actividad (Giuliano y Skliar, 2019). Este concepto de ocio, que es como se hace referencia en la Antigüedad a la skholè, tiene consigo una suspensión del exceso de acción para reorientar su movimiento hacia la contemplación, esto es, se pasa de la dirección a la desviación. ${ }^{11}$ No es de extrañar, en este orden de ideas, el consejo que Ulises le da a Aquiles cuando este último le recrimina a Agamenón por suspender su combate:

¡Aquiles, hijo de Peleo, el más sublime de los aqueos! Eres más fuerte que yo y me superas no poco con la pica, pero quizá yo en juicio te aventajo mucho, porque tengo más edad que tú y sé más cosas. Por eso tu corazón debe tolerar con paciencia mis consejos. Las gentes pronto se tornan hartas de contienda, pues es muchísima la paja que en ella el bronce vierte al suelo y poquísima la Cosecha cuando hace que se incline la balanza Zeus [...] No es con el estómago con lo que los aqueos lloran su muerte, pues demasiados y en rápida sucesión caen todos los días: ¿cuándo uno podría recobrar el resuello de esa faena? Sino que lo que hay que hacer es enterrar al que muera, manteniendo el ánimo implacable y llorándolo un solo día, y que los que sobrevivan del abominable combate no olviden la comida, ni la bebida para continuar con mayor encono y sin desmayo la lucha contra los adversarios, con el cuerpo revestido del intaladrable bronce (Hom. Il. XIX, 215-235).

Homero, en esta escena, representa la capacidad que tiene el desvío de la actividad dentro de la vida de cualquier sujeto. Contrario a lo que se puede suponer, la skholè tiene su propio rol dentro del existir, es un tipo especial de movimiento que se aleja del impulso que promueve Horme. Este último no es un estado constitutivo del movimiento del ser, la acción no está atada necesariamente a Horme, solo la acción como un appetitus, esto es, el actuar con esfuerzo, en demasía, hacia algo, especialmente utilizado en referencia al trabajo de los artesanos y mercaderes. Pero el hecho de que Horme esté vinculado en demasía con la acción humana, con el alma, no quiere decir que sea la que sirve de punto de origen para todo actuar humano.

Es allí donde la skholè tiene lugar. Más allá del dominio de la actividad hermanada con Eris, el pensamiento y la experiencia que surgen de este concepto de skholè traen consigo una forma de

11 Esta desviación rompía la rigurosidad del trabajo (tanto del campo como de las minas) para darle lugar a una capa social libre donde hay un tiempo y un espacio que posibilitan el pensar como vivencia (Botero, 2000, p. 63). 
comprender la actividad desde una perspectiva no limitada por la ambición y deseos humanos característicos en las actividades prácticas. Esta actividad contiene en su esencia una desviación de la esclavitud del trabajo o del deber del mismo, le es propia una libertad particular que rodea todo lo que resulta de actuar en la skhole.. ${ }^{12}$ El ser humano, entendido desde una actividad ajena a Horme, que bien que mal es una personificación que ata al ser humano a una racionalidad, se ubica en un lugar que llena de plenitud su existencia, la skholè posibilita un lógos que es libre y necesario para la narratividad que constituye toda relación humana dentro de una polis, ${ }^{13}$ en este sentido, con el ocio se forma un ritual que posibilita una comunidad con comunicación: ${ }^{14}$

Ocio, empero, me falta para exponer

toda su larga historia

con mi lira y blando sonido de voz,

de suerte que no llegue el hastío punzante. Lo que, empero,

ante mis pies va corriendo (lo inmediato),

lo que a ti se te debe, oh joven, la más reciente

de tus hazañas hermosas, alada camine por mi arte (Pi. P. viII, 30).

Con esta narración de Píndaro es posible apreciar una actividad productora que se le adjudica a la skholè. Esta última tiene varias dimensiones, sin que ninguna sea superior a la otra; una, que hace

12 Aristóteles va a darle prioridad a este concepto de skholè: "Esta actividad [la skholè] es la única que parece ser amada por sí misma, pues nada se saca de ella excepto la contemplación, mientras que de las actividades prácticas obtenemos, más o menos, otras cosas, además de la acción misma. Se cree, también, que la felicidad radica en el ocio, pues trabajamos para tener ocio y hacemos la guerra para tener paz" $(E N x, 7,5)$. La actividad del ocio está vinculada con la felicidad del ser humano, vivir desde el ocio permite un actuar libre que es el punto de convergencia para que el $\lambda$ ó $\gamma$ o $\varsigma$ tenga lugar dentro de la vida humana y, más aún, para que la eudaimonía sea la base de las relaciones humanas dentro de la polis (Mesa, 2017, pp. 39-41).

13 La investigación de Rechia y Cubas (2019) refleja este potencial formador que la skholè tiene dentro de su práctica contemporánea, lo cual demuestra cómo, aún tras el paso del tiempo, existe una potencia al interior del desvío de las intenciones del mercado.

14 Esto es, el ocio posibilita una forma especial de lógos contemplativo libre de toda Eris que impregne y corrompa lo sagrado del pensar. Así, se constituye un orden simbólico que da sentido a ciertos fenómenos que tienen lugar dentro de la cultura de la Grecia Antigua: "A la esencia de la fiesta pertenece la tranquilidad, en contraposición a la intranquilidad afanosa de lo cotidiano: una tranquilidad que reúne intensidad vital y contemplación y que incluso es capaz de reunirlas cuando la intensidad vital llega al desenfreno [...] Lo cotidiano, visto desde esta tranquilidad, aparece trivial y grotesco en su laboriosidad y en esa importancia que da a las cosas, pero en cambio aquello que cada día era lo más cotidiano y normal, aparece en la fiesta bajo una luz nueva y maravillosa, como algo digno de una fiesta especial" (Kerényi, 1999, p. 49). 
referencia al conocimiento; la segunda, que responde a lo social y, por último, aquella que lo vincula con lo ético-político. En lo referente a lo social, que es afín con su tercera dimensión, la skholè tiene una fuerza vinculante que produce un orden simbólico que libera al ser humano de la atadura del trabajo. Lo social, empero, no se separa de lo teológico, de la cosmogonía propia del griego en la Antigüedad, los símbolos y signos, significantes y significados, que se interrelacionan dentro del espacio-tiempo de la skholè. La dimensión social tiene una relación de realimentación con lo religioso, la desviación del trabajo es un tiempo sagrado de adoración. En la temporalidad que se vive con la skholè se da una fortificación de los modos de relación entre miembros de las polis. Horme tiene una capacidad de vincular, pero su relación con Eris fundamenta dicho vínculo desde la discordia como elemento característico, por lo que la ambición y la amargura, aún en su menor grado, desgastan el lazo que puede establecerse en el encuentro con los otros, de ahí que el trabajo, en esencia, se considere una actividad que posee una carga profana dentro de los procesos humanos que corresponden al alma. Contrario a la skholè, que fundamenta su actividad en la suspensión de la economización del ser para dar lugar a una relación socio-espiritual entre los miembros de una polis: $:^{15}$

Celebrando está el pueblo la fiesta del dios, una fiesta sacrosanta. ¿Quién hoy tirará con los arcos? Sentaos bien tranquilos. ¿Qué habrá de ocurrir si por caso dejamos esas hachas aquí? Yo no pienso que venga hombre alguno a robarlas entrando en las casas de Ulises Laertiada. Mas haced que el copero nos vierta el licor en las copas y libando en reposo dejemos el arco (Hom. Od. xxI, 260).

En lo que corresponde al trabajo alrededor de lo ético-político, la skholè es la espina dorsal de un régimen político funcional. ${ }^{16}$ Este

15 Con esto se indica que existe un relajamiento general que interrumpe el tiempo lleno cotidiano para dar lugar a un ritual de vinculación de lo mundano con lo eterno, del que surge una síntesis que constituye una experiencia de plenitud para el griego. Al dejarse de lado el trabajo se estructura otro tipo de tiempo (Burkert, 2007, p. 136).

16 Esto es así debido a la manera en la que la polis se articula como una amalgama polisémica en la que convergen múltiples sentidos (Almeyda, 2020, pp. 38-44). Por lo tanto, el trabajo y el ocio deben tener un lugar determinado dentro del funcionamiento apropiado de la comunidad política. 
ocio como principio ordenador de las leyes y las costumbres griegas permite una paz y un bienestar dentro de la polis, cuando se supera el trabajo en su entendimiento puramente impulsivo la constitución de un régimen toma otra dimensión; la virtud permite la vida más allá de la guerra, algo que Aristóteles encuentra como fundamental para que un sistema de gobierno sea funcional: "Los lacedemonios se mantuvieron mientras guerrearon, pero sucumbieron al alcanzar el mando, porque no sabían estar ociosos ni habían practicado ningún otro ejercicio superior al de la guerra" (Pol. II, 1271b34). Así, la skholè se entiende como un movimiento transformador y ordenante en lo que respecta a lo ético y lo político, su actividad se contrapone al appetitus guerrero de Horme, se fundamenta en una paz fundacional que gesta una estructuración formal de la vida en comunidad.

Finalmente, en lo correspondiente al conocimiento, la skholè pone un punto y aparte entre las ciencias orientadas al placer y a la necesidad para dar lugar a un pensamiento sagrado que es la base de todo filosofar, en sentido estricto, y de todo estudio de la physis. El conocimiento del mundo producto de la skholè es un ritual sagrado en el que se interrumpe la vulgaridad cotidiana, su banalidad centrada en la necesidad, para dar lugar a un lógos que agrada a los dioses:

A partir de este momento y listas ya todas las ciencias tales, se inventaron las que no se orientan al placer ni a la necesidad, primeramente en aquellos lugares en que los hombres gozaban de ocio: de ahí que las artes matemáticas se constituyeran por primera vez en Egipto, ya que allí la casta de los sacerdotes gozaba de ocio (Arist. Met., 981b).

Indagar sobre el conocimiento vía skholè implica una relación con la virtud sagrada que se eleva por encima de la tekhné que domina las labores cotidianas. Se habla de un tipo de ritual cercano al filosofar, inclusive, si se quiere, del reflexionar sobre la filosofía primera (refiriendo propiamente al pensamiento aristotélico). La paideia que surge del poner la skholè como principio epistemológico para pensar dentro de una polis abre lugar a un tipo sagrado de formación humana, no es un aprendizaje orientado a la riqueza como finalidad, sino que constituye una felicidad como fin en sí mismo y 
como parte de la misma skholè. ${ }^{17}$ Así, la idea de una vida fuera del trabajo tiene una relación compenetrada entre lo social, lo éticopolítico, lo epistemológico y, por extensión, lo educativo. ${ }^{18}$ La skholè es requisito para la búsqueda existencial de la felicidad, de ahí la importancia que el griego veía en la interrupción del dominio de Horme sobre el alma humana.

Así, el ocio que surge dentro del entendimiento del mundo griego tiene un carácter divino donde lo mundano y lo superior se vinculan en un ritual de interacción en el que los dioses, en su pleno descanso con el mundo, propician un espacio y un tiempo en el cual el ser humano, que ahora se distrae en este último, contrario al trabajo, que concentra a la humanidad en sí misma y en su oficio, puede establecer un encuentro con su propia cultura y sociedad en una relación no economizada. El trabajo no forma parte de la fiesta griega, el ocio como una ritualidad religiosa vincula a todos con todos en su individualidad para interrumpir la atadura del trabajar. La skholè no convive con Eris ni en su bendición ni en su amargura, las bendiciones del trabajo, que están fuertemente relacionadas con Ares ${ }^{19}$ son dejadas de lado por los hombres rectos, que conocen los

17 Byung-Chul Han es consciente de esta fuerza que tenían los griegos a la hora de entender la skholè como un tiempo distinto en el cual la comunidad se direcciona a una sabiduría superior: "El tiempo sublime, como el de las nupcias, es también la temporalidad de la escuela superior. En griego antiguo 'escuela' se decía scholé, es decir, ociosidad. La escuela superior es por tanto una ociosidad superior" (Han, 2020, p. 59). Igualmente, Jaeger ve en el concepto de paideia un antecedente que es producto del ocio, el cual constituye el balance del cuerpo con el espíritu (1996, pp. 71).

18 Pierre Bourdieu entiende la capacidad subyacente en la skholè; sus Meditaciones pascalianas resaltan el modo en el que el tiempo de ocio es un tiempo libre que se des-ata de la economía de la vida: "El tiempo vacío que hay que matar se opone al tiempo lleno (o bien aprovechado) de quien está sumido en los quehaceres [...] Pero se opone asimismo [el tiempo lleno] a la scholé, tiempo empleado libremente para fines libremente escogidos y gratuitos que, para el intelectual o el artista, por ejemplo, pueden ser los de un trabajo liberado, en su ritmo, su momento y su duración, de cualquier imposición externa y, en particular, de la que se impone mediante sanción monetaria directa" (Bourdieu, 1999, pp. 296-297). En este sentido, la skholè es parte de una práctica de la temporalidad humana que se opone a la a-skholè, la prisa.

19 Esto es algo que es propio del carácter divino de Ares, quien entra y disfruta de todo lo que ocasione luchas, disputas y riñas entre los seres humanos. De esto último viene la sentencia que Zeus le lanza a este en la Ilíada: "Eres para mí el más odioso de los dioses dueños del Olimpo, pues siempre te gustan la disputa, los combates y las luchas. Tienes el furor incontenible e irreprimible de tu madre, de Hera, a la que yo sólo a duras penas doblego con palabras" (Hom. Il. v, 890). 
límites de sus labores para poder evitar la hibris que las fortunas de Horme pueden desencadenar:

Jamás el hambre ni la ruina acompañan a los hombres de recto proceder, sino que alternan con fiestas el cuidado del campo [...] A quienes en cambio sólo les preocupa la violencia nefasta y las malas acciones, contra ellos el Crónida Zeus de amplia mirada decreta su justicia. Muchas veces hasta toda una ciudad carga con la culpa de un malvado (Hes. Op., 230-240).

La economización del ser, a la que Horme tiende por su condición de deidad útil para la vida cotidiana, se encuentra en contraste con la skholè, que interrumpe la producción en favor de la adoración, el ocio armoniza la comunidad. El ciudadano debe interrumpir el trabajo para poder ubicarse en el mundo en el que vive, de modo que pueda ver su polis como algo más allá de un medio para alcanzar un fin personal. El trabajo, ya sea por esclavitud o libertad, profana lo sagrado de la vida superior, la cual descansa en la la ociosidad; no obstante, no puede eliminarse de la vida el trabajo, ya que el mundo se sostiene sobre lo mundano que la tekhné produce. Esto último indica que el hombre recto se sostiene en el justo medio entre lo sagrado y lo profano; empero, la vida cotidiana tiende a mantener el trabajo, a Horme, como la condición que domina la vida. ${ }^{20}$ De ahí la importancia que tiene para el griego la skholè, en concreto, para los individuos considerados virtuosos. Sin embargo, existe algo en el ocio que debe ser objeto de profundización para entender su rol dentro del contexto cosmogónico griego.

\section{Ergía y Pasítea: hacia una ontología de la pereza}

La skholè no es una cualidad ontológica del ser en su estar-enel-mundo, más bien, esta idea de ocio es un estado especial al que llega el ser a partir de la conjugación de otros elementos que sí son intrínsecos a la esencia del alma humana. Es en este punto donde se introduce la primera relación cosmogónica que permite encontrar

20 Es que esta relación del pueblo griego con lo eterno permite que lo cotidiano tenga un valor metafísico: "El valor de un pueblo [...] se mide precisamente por su mayor o menor capacidad de imprimir a sus vivencias el sello de lo eterno: pues, por decirlo así, con esto queda desmundanizado" (Nietzsche, 2004, p. 192). Lo metafísico de la vida se halla en la necesidad de enlazar los mitos con las vivencias, comprendiendo estas últimas solo por medio de dicho enlace. 
una conexión entre la importancia del ocio en la vida del ser humano y una mirada onto-teológica. La skholè no es una deidad del panteón griego, su lugar dentro de las prácticas del mundo antiguo, entonces, pareciera estar fundamentado a partir del papel que el mismo lógos le da para poder pensar contemplativamente el mundo fuera de las ataduras y esclavitud de la actividad, en especial aquella que corresponde al trabajo. Skholè y lógos parecieran estar vinculados, la razón es la que le da su lugar al ocio, lo captura para que le sea útil. Sin embargo, las relaciones teológicas que componen la idea griega de ocio la imposibilitan para la utilidad y la economización, esto es, más allá de la necesidad de la skholè para la búsqueda de la verdad y la contemplación de lo bello y lo bueno por medio de la especulación, el ocio tiene una razón de ser que viene precedida cosmogónicamente; para demostrar esto último hay que recurrir a dos entidades: Ergía (Pereza) y Pasítea (Relajación), quienes son fundamentales para profundizar en el noactuar que constituye lo humano.

Opuesta a Horme, Ergía responde más adecuadamente a aquellas cualidades que son la esencia de lo humano; contrario al cansancio, que se establece como un momento que es producto de una acción, esto es, el cansancio surge de realizar una actividad de algún tipo. Avanzando en esta última idea, el estar-cansado es la combinación de la pereza y la actividad, lo cual origina un estado intermitente que le permite al ser ubicarse en el mundo desde una mirada distinta. ${ }^{21}$ La pereza, que en este caso se personifica en Ergía, trae consigo una profundidad que cala más hondo en la constitución de lo humano; esta no requiere de ningún momento previo para surgir, sino que tiene lugar allí mismo en la pura creación, no requiere de un afuera que la impulse a salir, sino que, en cuanto que, en tanto que deidad, es inmanente a la esencia humana, su misma creación afirma esta idea:

21 Peter Handke (1990) es consciente de la cualidad existencial que está depositada en el estar-cansado: "Estos cansancios no se pueden planificar; no pueden ser una meta que uno se proponga. Pero sé también que jamás llegan sin fundamento, sino siempre después de una fatiga, en la transición, después de haber superado algo. Y ahora levantémonos y salgamos, afuera, a las calles, a estar con la gente, para ver si tal vez en este tiempo, un cansancio pequeño, común, nos hace una seña y nos cuenta algo" $(1990$, p. 83). El cansancio resulta de, no surge de la nada, requiere de un estímulo externo que atraviese al individuo, allí radica su elemento característico que lo distancia de la pereza. Esta última es, más bien, inmanente, mientras que el cansancio tiene una orientación existencial. 
Del Éter y la Tierra vinieron el Dolor, el Engaño, la Ira, el Luto, la Mentira, el Juramento, la Venganza, la Autoindulgencia, la Pelea, el Olvido, la Pereza, el Miedo, la Arrogancia, el Incesto, la Lucha, el Océano, Temis, Tártaro y Ponto; y los Titanes, Briareus, Gyges, Steropes, Atlas, Hyperion y Polus, Saturno, Ops, Moneta, Dione y las tres Furias (Alecto, Megaera, Tisiphone) (Hyginus, Fab., 2007, p. 95).

De este modo, se puede entender que el origen de Ergía la convierte en una divinidad que surge de lo más íntimo que compone el mundo, el aire y la tierra. Más allá de ser pensada como un elemento que encarna una molestia por su proximidad con la holgazanería, la cual era fuertemente criticada, la pereza que aquí se encarna refiere a un tipo especial de categoría ontológica para el ser humano. La ausencia de un elemento externo que la detone la vuelve inmanente a este último, por lo que su presencia no puede ser borrada de tajo por más que Horme se haga presente. Ergía es la base cosmogónica que da razón de ser a la skholè, que implica una inactividad (un no-actuar), un tiempo libre del peso de la acción, aunque sin renunciar plenamente al impulso que dicho actuar tiene para producir. Sin embargo, el único modo de mantener el alma templada frente a la carga que implica Horme es por medio del entendimiento de su opuesto, esto es, de Ergía. El descanso que interrumpe el trabajo es producto del cansancio, pero este no puede ser resultado de la pura actividad, esto es, una cosa no puede surgir de su opuesto. ${ }^{22}$ Por ende, si Horme, en cuanto que actividad inherente al ser humano, requiere de un contrario que se encuentre en condiciones iguales, puesto que solo así puede una cosa ser reducida por otra, es ahí donde entra Ergía. Esta deidad forma parte del estar-en-el-mundo de los seres humanos, por lo tanto, siempre que aparece el trabajo está acompañado de una pereza. Esta última es la que armoniza el alma y, a su vez, evita el castigo de los dioses por hibris. ${ }^{23}$ Ergía posibilita la skholè y auspicia

22 Esto es así ya que, en la tradición del pensamiento occidental, la lógica aristotélica marca un punto de referencia que justifica el cómo se entienden sus propios mitos y, más aún, la realidad en sí misma. Esto último no aplica para el pensamiento de Oriente, por ejemplo, ya que este posee una lógica paradójica que posibilita otros horizontes interpretativos (Suzuki y Fromm, 1994, p. 111).

23 Lafargue encuentra en la pereza un regalo de los dioses: "Los filósofos de la antigüedad enseñaban el desprecio por el trabajo, esa degradación del hombre libre, mientras los poetas cantaban a la pereza, ese presente de los Dioses" (1970, p. 13). Para este autor, la pereza implica una relación entre mito y civilización que no debe dejarse de lado. 
una paz en la polis al crear un puente entre lo profano y lo sagrado, el descanso que llega con la pereza es la piedra con la que choca la a-skholè, la prisa, lo que da lugar a ese tiempo sagrado en el que se propician espacios rituales de vinculación entre todos los miembros de una comunidad. 24

No obstante, aunque la pereza es algo inmanente para el griego, debido a la manera en la que sus propias creencias así se lo dan a entender, Ergía, ya que no es autónoma, no puede hacerse manifiesta plenamente sin su deidad hermana: Pasítea. Esta última tiene la capacidad de poner en movimiento esta inactividad pura que la pereza tiene como carácter intrínseco, puesto que solo la relajación puede presentarse como un sentimiento que conecta a Ergía con los demás dioses y personificaciones que forman el mundo griego:

Más allá de las cámaras envueltas por las nubes de la penumbra occidental y el otro reino de Etiopía, se alza un bosquecillo inmóvil, impenetrable por cualquier estrella; debajo de él, los huecos recovecos de una cueva profunda y rocosa se adentran en una montaña, donde la mano lenta de la naturaleza ha establecido los pasillos del sueño perezoso y su morada tranquila. El umbral está custodiado por el sombrío Silencio y el aburrido Olvido y la tórpida Pereza con semblante siempre somnoliento. Relajación, con las alas plegadas, se sienta muda en la explanada y empuja los vientos violentos desde la azotea, y prohíben que las ramas se balanceen y quiten sus gorjeos a los pájaros (Statius, Theb. x, 100).

Este comité de dioses (Silencio, Olvido y Pereza) son los guardianes de Hipnos y es precisamente esta condición de guardianes

24 Dicho tiempo, que se caracteriza por festividades sagradas y por una vida de intensidad religiosa, es requerido para poder mantener el alma y la tranquilidad entre mortales y dioses, como bien lo advierte Durkheim en su estudio sobre la vida religiosa: "[E]1 trabajo es la forma eminente de la actividad profana: no tiene otra finalidad aparente que satisfacer las necesidades temporales de la vida; no nos pone en contacto más que con cosas ordinarias. Por el contrario, en los días de fiesta la vida religiosa alcanza un grado de excepcional intensidad. El contraste entre esos dos tipos de existencia se hace en tales momentos particularmente aparente; por ello no pueden estar juntos. El hombre no puede aproximarse íntimamente a su dios cuando aún lleva sobre sí las marcas de su vida profana; de manera inversa, no puede volver sobre sus ocupaciones usuales cuando acaba de ser santificado por el rito" (1982, p. 286). La pereza, entonces, como una categoría ontológica del ser humano que se justifica desde la religión politeísta de la Grecia Antigua, es una parte vital dentro del entendimiento que el ser humano hace de su actuar mundano y trascendental, no es un solo estado pasajero, es una cualidad intrínseca que posibilita un tiempo libre. 
la que los ubica como agentes pasivos que no tienen la capacidad de movilizarse por sí mismos; hay que agregar que, así como con la pereza, Olvido y Silencio forman parte de estas deidades que son constitutivas a la existencia del ser humano, aunque acá solo se desarrolla en detalle Ergía por motivos meramente metodológicos. Pasítea, en este orden de ideas, es la única que engendra movimiento; aunque no es guardiana del sueño, su presencia hace posible ubicarla como una entidad que conecta, con su violento aletear, la cueva del bosque con el resto del mundo. De ahí que su compañía con Ergía sea algo cosmológicamente explicado y no algo conjetural; la pereza se encarga de velar por los intereses de Hipnos y, por lo tanto, su cualidad de interrumpir el dominio de Horme es parte de su naturaleza divina, por lo que la pereza, como parte de la constitución del alma humana, quiere hacer un retorno al sueño en tanto que este permite un tiempo de renovación dentro del ser-en-el-mundo de la humanidad..$^{25}$

Así, Pasítea es parte de la red que posibilita la skholè, ya que es en su actuar limitado y permeado por Ergía e Hipnos que se vuelve realidad la interrupción de una deidad tan adorada y útil como lo es Horme. Y esto no es algo aleatorio, la fidelidad de esta diosa se justifica en el matrimonio que existe entre Pasítea e Hipnos, el cual hace que el sueño pueda calmarse y acontecer en la vida humana sin perturbaciones: “¡Sueño! ¿Por qué te angustias con eso [...]? Ve, y yo una de las juveniles Gracias te daré en matrimonio y para que sea llamada esposa tuya, a Pasítea, que es a la que sin cesar anhelas todos los días" (Hom. Il. XIV, 265-269). El compromiso de los guardianes, entonces, está vigilado por la mismísima cónyuge del sueño, por lo que existe una estructura mitológica que justifica el papel de estas deidades menores dentro del alma y la realidad humanas.

Ahora bien, en la práctica, Pasítea tiene una naturaleza que coincide con la de sus padres: Hera y Dioniso. ${ }^{26}$ Esto indica que la

25 Este tipo de renovación da lugar a una pereza creativa (Albornoz, 2016, p. 4), en la que existe una conciliación entre estas deidades, lo cual hace posible una armonía existencial.

26 Esto se afirma así por Nonnos: "¡No provoques a la madre de Pasítea, Hera, la esclava del amor conyugal!" (Dion. II xxxi, 173); y: "Mientras los indios corrían borrachos por los cerros, justo en ese momento el dulce Sueño desplegaba su ala vigorosa, asaltando los ojos vacilantes de los indios persistentes y los metía en la cama para atormentarlos 
relajación es heredera de una tradición de ritualidad, festejo y del éxtasis junto al compromiso y los celos. El carácter divino de la relajación está consagrado no con una simple interrupción ocasional o momentánea, sino que el umbral que esta crea en el tiempo lleno es una ruptura divina que se fundamenta en la necesidad de acabar con la hegemonía de la desgastante Horme. La relajación, entonces, es un elemento vigilante y actuante pero no inmanente, como lo son el olvido, el silencio y la pereza, ya que su presencia puede ir y venir dentro del alma humana, aunque esto no la hace incapaz de enfrentarse a la ruina producida por el esclavizante trabajo. Esto quiere decir que Pasítea, a pesar de generar movimiento, está limitada por los guardianes del sueño, debido a que estos están imbuidos con mayor profundidad en la constitución del ser, pues por más que se presente Horme, la pereza, junto con el olvido y el silencio, no desaparecen por ser creación de la tierra y el cielo, y su origen divino los convierte en parte intrínseca de lo humano; sin embargo, los guardianes necesitan de la movilidad que produce la relajación para cumplir su tarea divina de defender a Hipnos. Este conflicto de intereses hace que se forme una alianza entre estas deidades, la cual se ve reflejada en el mundo de los humanos.

De este modo, se puede afirmar que esta lucha entre Ergía y Pasítea contra Horme es eterna y es una normalidad dentro de la temporalidad y la espacialidad del mundo griego. Dicho conflicto tiene un alcance más profundo, ya que corresponde al duelo del alma entre lo racional y lo irracional. ${ }^{27}$ Esta batalla surge allí donde estas deidades se encuentran, pues está en su naturaleza la lucha por

mentalmente por el vino inmoderado lo que hacía gracia al padre de Pasítea, Dionisos" (Dion. I xv, 87).

27 Esto es así, en parte, por la irracionalidad que es propia del griego en cuanto que ser incrustado en un mundo cosmogónicamente fundamentado por el mito y, después, en la razón (Laso, 1993, pp. 26-34). Para el griego en la Antigüedad, la pereza y la relajación hacen parte de la irracionalidad que les es propia y que alcanza su culmen al dar acceso al dormir: "El mundo del sueño [en la Antigüedad] nos ofrece la posibilidad de comunicarnos, por fugazmente que sea, con nuestros amigos distantes, nuestros muertos y nuestros dioses. Para los hombres normales, es la única experiencia en que escapan de la servidumbre molesta e incomprensible del tiempo y del espacio" (Dodds, 1997, p. 103). Claro está que la skholè es parte de una experiencia distinta que se lleva a cabo en la vigilia, pero no por eso se excluye de una relación con los sueños. 
ver quién tiene el dominio sobre la vida humana. ${ }^{28}$ Este conflicto está dividido, por un lado, principalmente por la relajación, que es aquella que puede movilizarse y quien tiene el impulso de los demás guardianes del sueño, mientras que, por el otro, Horme por sí sola tiene en su carácter la capacidad de imponerse en la cotidianidad humana. A pesar de la, en apariencia, preferencia por el trabajo duro, realmente los guardianes del sueño logran ejercer un dominio dentro del tiempo y el espacio de la humanidad, lo cual logra una paz al interior del alma humana que se encuentra en una tensión entre ambas deidades.

\section{Conclusión}

Ergía constituye parte de la esencia humana, no puede ser dejada de lado, no puede reprimirse, como una "disposición a": siempre está direccionada a la inactividad, su cualidad característica es la no-acción; por lo mismo, esta deidad no puede exteriorizarse al mundo, solo puede mantenerse como guardiana al interior del ser, es inmanente y no sale de su hogar, carece de autonomía, de ahí que su existencia implique una forma exterior de interactuar con el mundo, y es allí donde entra Pasítea, quien hace presencia ante esta guardiana de Hipnos (sin dejar de lado que también están presentes Olvido y Silencio) para poder llevar su carácter al resto de la existencia por medio del aleteo de sus alas. Ahora bien, la razón ritual para entender el lugar de la pereza en la Antigüedad se encuentra en su relación con el sueño, ya que es tras los significados que se esconden detrás de esta deidad que se articula todo un esquema interpretativo al respecto del rol que juega la pereza, y, por extensión, la relajación, dentro de la sociedad en la Antigua Grecia. Hipnos encuentra su posibilidad de ocurrir por medio de la pereza, y, por ende,

28 Aristóteles, a pesar de que no encuentra en el mito la explicación al balance entre sueño y vigilia, sí encuentra que ambas se complementan mutuamente y, de este modo, se hace posible una experiencia completa de la vida: "De modo similar es obvio que no hay nada que esté siempre despierto o que esté siempre durmiendo, sino que se dan mutuamente en los mismos animales ambas afecciones. Pues si hay algún animal no dotado de sensación, no es posible que duerma ni que esté despierto, ya que ambas son afecciones de la facultad sensible primera" (Arist. Somn.Vig., 454a). 
de la relajación, de lo contrario estaría confinada a no acontecer, pero como el alma humana siempre requiere de la bendición del sueño (así lo demuestra la vida), sus condiciones de posibilidad son un imperativo irreductible, de ahí que Ergía, como condición ontológica, y Pasítea, como posibilidad factual, no se puedan separar del alma humana.

La vida onírica, como parte de la vida simbólica griega, ${ }^{29}$ compone una experiencia de la que todo ser humano debe formar parte, constituye un ritual que vincula a toda la comunidad, por lo que la pereza debe siempre hacerse presente por medio de la relajación para tomar el control de la existencia humana y separar el mundo del actuar del de la inactividad. Claro está, en el proceso para llegar al sueño existen una multiplicidad de estados que atraviesan la vida inactiva, esta última se puede extender como parte de la vita contemplativa, la skholè es un ejemplo de ese estado previo al misterioso mundo de los sueños, esta última no es ajena a las posibilidades experimentales que el estudio de los sueños pueda realizar. ${ }^{30}$ Sin embargo, este ejercicio de imponerse ante Horme solamente ocurre por medio de una concatenación que permite al ser humano descansar, distraerse en el mundo, y es allí donde entra Ergía, en alianza con Hipnos, Pasítea y los otros guardianes, para instaurar los umbrales entre vita activa y vita contemplativa. La pereza auspicia el lugar para la skholè e interrumpe el tiempo lleno para dar paso a un tiempo vacío, el cual, por su misma condición de ausencia, instaura una presencia especial en la cual el ser humano puede deslocalizarse

29 En este sentido, la experiencia de Ergía y Pasítea escapa de la racionalidad del lógos para producir un tipo de verdad desde el misterio de la divinidad, de ahí que estas deidades tan cercanas a Hipnos huyen de la banalidad cotidiana de lo profano para ubicarse en la vida simbólica: "Sólo la vida simbólica puede expresar la necesidad del alma, la necesidad diaria del alma. Y como la gente no tiene esta cosa, nunca podrá salir de esta trampa, de esta vida horrible y banal en la que no somos 'nada más que'. En el ritual estamos cerca de la divinidad, somos divinos" (Jung, 2016, p. 262).

30 Es que el dominio del estudio de los sueños constituye una manera de revelar la aletheia que el mundo de la vigilia no permite, de ahí la conclusión que Cappelletti saca de su estudio sobre el sueño en la Antigua Grecia: "Mientras el cuerpo duerme, no siente; pero el alma, despierta, posee el conocimiento, ve, escucha, toca, camina, se contrista, se acuerda y realiza en el breve espacio que ocupa, durante el sueño, todas las funciones del cuerpo y el alma. Por eso, quien sea capaz de juzgar la actividad onírica del alma correctamente poseerá una gran parte de la ciencia" (Cappelletti, 1989, p. 41). Adorno (2008) demuestra precisamente esta idea de la aletheia detrás del sueño. 
y entregarse a lo sagrado. La banalidad de lo profano se pierde en el mundo de Hipnos, pero solamente se puede acceder a él con el permiso de Ergía.

Ahora bien, si se parte de la tesis de que "[e]l mito no se destruye, sólo se transforma. Y Occidente debe su base a estas explicaciones cuyas consecuencias aún siguen tan vivas como antes. Su cimiento es el relato mítico" (Flantrmsky, 2010, p. 115), es posible encontrar en la pereza un objeto de análisis filosófico interesante. Al no poner su énfasis en el actuar stricto sensu, la fuerza creativa de la pereza surge a partir de una amalgama que tiene por base el no-actuar. De esta forma, es posible para el ser humano reencontrarse con una dimensión de su propia existencia que ha sido negada por el dogma del trabajo duro. Este último ha estado presente a lo largo de toda la historia de la humanidad, más aún con el advenimiento de la industrialización y el capitalismo (Lafargue, 1970). La explicación cosmogónica de la pereza permite dar paso a un nuevo tipo de paradigma subjetivo en el que, frente al dogma del trabajo duro, se impone una pereza revolucionaria, la cual "puede ser una respuesta a esta represión [del actuar como estructura de coacción], una táctica subjetiva" (Barthes, 2005, p. 286), la cual hace posible superar el desgaste producto del constante dominio de Horme a lo largo de la vida e historia humana para dar lugar a una sociedad interrumpida en la que, lejos del peso de una subjetividad predominantemente económico-empresarial (homo øeconomicus), surge un polo a tierra que anula el carácter autodestructivo que se hace presente al vivir bajo el dominio de dicho dogma. ${ }^{31}$

Así, la pereza se torna revolucionaria cuando el orden del mundo se ha convertido en puro trabajo, cuando el tiempo ha devenido lleno.

31 Esto es algo que Thoreau (2015) criticaba del espíritu comercial que veía en su tiempo: "Este mundo curioso en el que habitamos es más maravilloso que conveniente, más bello que útil y, por tanto, existe más para ser admirado y disfrutado que utilizado. Debería alterarse el orden de las cosas: el séptimo día debería ser el día del trabajo de los hombres, el día en que se ganasen la vida con el sudor de su frente, y los otros seis [...] en los que arreglar su extenso jardín y beber las suaves influencias y sublimes revelaciones de la naturaleza" $(2015$, p. 16). Este nuevo orden, siguiendo a Thoreau, surge rompiendo, desde el individuo, el dominio del trabajo duro orientado a la pura acumulación de riqueza, esto es, escapando de la esclavitud del trabajo sin descanso. 
Ergeía, y Pasítea por extensión, permite completar la pregunta sobre si el ser humano es perezoso por naturaleza (Fromm, 1995), ya que reafirma el lugar de unas deidades que son parte, como se expuso anteriormente, de los cimientos mitológicos de Occidente, dando un sí a la pregunta sobre la pereza natural de los seres humanos a partir, más que de fundamentos psicológicos o biológicos, como lo hace Fromm, del pensamiento mitológico (Lévi-Strauss, 1990).

Este fundamento cosmogónico ayuda a pensar cómo la pereza puede ser un freno de emergencia (Benjamin, 2008, p. 70) que detenga los engranajes de la producción, la competencia y el rendimiento que dominan la actualidad; sépase, Ergía, de la mano de Pasítea, puede fracturar la dinámica hegemónica del tiempo lleno que ha surgido con el dominio histórico de Horme. El no-actuar, entonces, se caracteriza por el no hacer nada, esto es, la capacidad de suspender e interrumpir la locomoción diaria del trabajo que moldea al ser humano, ${ }^{32}$ para lo cual la pereza es fundamental, ya que es una fuerza vaciada que se burla de la racionalidad a la que está sujeta toda la empleabilidad de la vida. Lo dicho indica que la pereza rompe con la construcción de la subjetividad que el trabajo duro produce: "[...] esta ruptura de construcción, sea voluntaria o no, indica bien que en las situaciones de pereza el sujeto está casi desposeído de su consistencia de sujeto. Está descentrado, no puede ni siquiera decir 'yo'. Esta sería la verdadera pereza" (Barthes, 2005, p. 289). Así, el pensamiento mitológico que sustenta a Ergía y Pasítea sienta las bases para una alternativa desde el plano subjetivo para poder pensar nuevas formas de vida que en lugar de estar atadas a las cadenas esclavizantes del yo-que-trabaja, puedan, como dice Thoreau, beber de las suaves influencias y sublimes revelaciones de la naturaleza $\mathbf{C}$

Onfray (2011) es muy consciente de este proceso de desvanecimiento del cuerpo del individuo frente al peso del trabajo duro y sin descanso: "[N]o hay peor esclavitud que la de sentir, poco a poco, que la propia carne se moldea, se deshace y se reconstituye en torno a los imperativos del trabajo" (pp. 18-19). En este sentido, el trabajo construye un modelo de persona, y es deber de la pereza romperlo. 


\section{Referencias}

Adorno, T. (2008). Sueños (A. Brotons, Trad.). Akal.

Albornoz, S. (2016). (Acerca de la) Pereza. Laboreal, 12(1), 1-5. http://dx.doi. org/10.15667/laborealxii0116sa

Almeyda, J. (2020). Aristóteles y Tomás de Aquino: un análisis en torno a la polis y la res publica. Revista Filosofía UIS, 19(1), 35-58. https://doi. org/10.18273/revfil.v19n1-2020011

Aristóteles. (1987). Acerca del sueño y de la vigilia [Somn.Vig.]. En Acerca de la generación y la corrupción. Tratados breves de historia natural (E. La Croce y A. Bernabé, Trads., pp. 257-276). Gredos.

Aristóteles. (1988). Política [Pol.] (M. García, Trad.). Gredos.

Aristóteles. (1994). Metafísica [Met.] (T. Calvo, Trad.). Gredos.

Aristóteles. (1998). Ética Nicomáquea [EN]. Ética Eudemia [EE] (J. Pallí Bonet, Trad.). Gredos.

Barthes, R. (1993). Fragmentos de un discurso amoroso (E. Molina, Trad.). Siglo XXI.

Barthes, R. (2005). Atrevámonos a ser perezosos. En El grano de la voz: Entrevistas 1962-1980 (N. Pasternac, Trad., pp. 286-292). Siglo XXI.

Benjamin, W. (2008). Tesis sobre la historia: apuntes, notas y variantes. En Tesis sobre la historia y otros fragmentos (B. Echeverría, Trad., pp. 61-118). UACM/Editorial Ítaca.

Botero, A. (2000). La relación entre la filosofía y la medicina desde la Antigüedad hasta el Medioevo. Escritos, (27), 62-83.

Bourdieu, P. (1999) Meditaciones pascalianas (T. Kauf, Trad.). Anagrama.

Burkert, W. (2007). Religión griega: Arcaica y Clásica (H. Bernabé, Trad.). Abada.

Cappelletti, Á. (1989). Las teorías del sueño en la filosofía antigua. Fondo de Cultura Económica.

Cicero. (1928). De Officiis [Off.] (W. Miller, Trad.). The Loeb Classical Library. 
Dodds, E. (1997). Los griegos y lo irracional (M. Araujo, Trad.). Alianza.

Durkheim, É. (1982). Las formas elementales de la vida religiosa (R. Ramos, Trad.). Akal.

Flantrmsky, O. (2010). Culpa y civilización: una lectura al mito de Dioniso Órfico y al mito de la caída de Adán. Revista Filosofía UIS, 9(2), 89. 117.https://revistas.uis.edu.co/index.php/revistafilosofiauis/article/ view/1596

Fromm, E. (1995). El hombre ¿es perezoso por naturaleza? En La patología de la normalidad, (E. Fuente, Trad., pp. 131-178). Paidós.

Giuliano, F. y Skliar, C. (2019). A propósito de la pereza y la scholè. Meditaciones éticas, políticas, educativas. Archivos de Ciencias de la Educación, 13(16), 1-16. https://doi.org/10.24215/23468866e072

Han, B-C. (2020). La desaparición de los rituales: Una topología del presente (A. Ciria, Trad.). Herder.

Handke, P. (1990). Ensayo sobre el cansancio (E. Barjau, Trad.). Alianza.

Hesiod. (2006). Theogony, Works and days [Op.], Testimonia (G. Most, Trad.). Loeb Classical Library \& Harvard University Press.

Hesíodo. (1978a). Teogonía [Th.]. En Obras y fragmentos (A. Pérez Jiménez y A. Martínez Díez, Trads., pp. 63-114). Gredos.

Hesíodo. (1978b). Trabajos y días [Op.]. En Obras y fragmentos (A. Garzón y A. Martínez, Trads., pp. 115-168). Gredos.

Homero. (1993). Odisea [Od.] (J. Pabón, Trad.). Gredos.

Homero. (1996). Ilíada [Il.] (E. Crespo, Trad.). Gredos.

Hyginus. (2007). Fabulae [Fab.]. En Apollodorus' Library and Hyginus' Fabulae: Two Handbooks of Greek Mythology (S. Smith \& S. Trzaskoma, Trads., pp. 95-182). Hackett Publishing Company.

Jaeger, W. (1996). Paideia: Los ideales de la cultura griega (J. Xirau y W. Roces, Trads.). Fondo de Cultura Económica.

Jenofonte. (1993a). Recuerdos de Sócrates [Mem.]. En Recuerdos de Sócrates. Económico. Banquete. Apología de Sócrates (J. Zaragoza, Trad., pp. 7-200). Gredos. 
Jenofonte. (1993b). Económico [Oec.]. En Recuerdos de Sócrates. Económico. Banquete. Apología de Sócrates. (J. Zaragoza, Trad., pp. 201-292). Gredos.

Jung, C. (2016). Vida simbólica. En La vida simbólica. Obra completa, vol. 18/1 (J. Navarro, Trad., pp. 255-280). Trotta.

Kerényi, K. (1999). La religión antigua (A. Kovacsis y M. León, Trads.). Herder.

Lafargue, P. (1970). El derecho a la pereza (J. Giner, Trad.). Grijalbo.

Laso, E. (1996). Pensamiento mítico y pensamiento racional. En E. Díaz (Comp.), La producción de conceptos científicos (pp. 26-34). Biblos.

Lévi-Strauss, C. (1990). Mito y significado (H. Arruabarrena, Trad.). Alianza.

Mesa, D. (2017). Elementos formales de la felicidad. Una lectura no comprensiva de Aristóteles. Revista Filosofía UIS, 16(2), 19-42. https:// doi.org/10.18273/revfil.v16n2-2017001

Nietzsche, F. (2004). El origen de la tragedia o Grecia y el pesimismo (A. Sánchez Pascual, Trad.). Alianza.

Nietzsche, F. (2013). La lucha de Homero. En Ensayos sobre los griegos (F. González, Trad., pp. 57-70). Ediciones Godot.

Nonnos. (1940a). Dionysiaca I [Dion. I] (W. Rouse, Trad.). Loeb Classical Library.

Nonnos. (1940b). Dionysiaca II [Dion. II] (W. Rouse, Trad.). Loeb Classical Library.

Onfray, M. (2011). Política del rebelde. Tratado de resistencia e insumisión (M. Galmarini, Trad.). Anagrama.

Pausanias. [Paus.]. (1994). Descripción de Grecia. Libros I-II (M. Herrero, Trad.). Gredos.

Píndaro. (1984a). Píticas [P.]. En Odas y fragmentos (A. Ortega, Trad., pp. 141-216). Gredos.

Píndaro. (1984b). Nemeas [N.]. En Odas y fragmentos (A. Ortega, Trad., pp. 217-274). Gredos. 
Platón. (1988). República [R.]. Diálogos IV (C. Eggers, Trad.). Gredos.

Rechia, K. y Cubas C. (2019). Una skholé para profesores: el estudio como dimensión constitutiva del oficio de profesor. Teoría de la Educación, 31(2), 109-130. http://dx.doi.org/10.14201/teri.20862

Saavedra, J. (2007). Las ideas sobre el hombre en la Grecia antigua. Revista Facultad de Ciencias Económicas: Investigación y Reflexión, 15(2), 213. 234. https://www.redalyc.org/pdf/909/90915212.pdf

Statius. (1928). Thebaid V-XII [Theb.] (J. Mozley, Trad.). The Loeb Classical Library.

Suzuki, D. y Fromm, E. (1994). Budismo zen y psicoanálisis (J. Campos, Trad.). Fondo de Cultura Económica.

Thoreau, H. (2015). El espíritu comercial de los tiempos modernos. En Desobediencia: Antología de ensayos políticos (L. Naranjo, C. Torres y M. Nava, Trads., pp. 15-18). Errata Naturae.

Vernant, J. (1983). Mito y pensamiento en la Grecia antigua (J. López, Trad.). Ariel.

Vernant, J. (2000). El universo, los dioses, los hombres: El relato de los mitos griegos (J. Jordá, Trad.). Anagrama.

Vernant, J. (2003). Mito y sociedad en la Grecia antigua (C. Gázquez, Trad.). Siglo XXI. 